\section{Successful Bendamustine Desensitization for a Delayed-Type Hypersensitivity Reaction}

Martin Garcia $\mathrm{C}^{1}$, Sierra Pacho $\mathrm{M}^{2}$, Moreno Rodilla $\mathrm{E}^{3}$, Callejo Melgosa $\mathrm{AM}^{1}$, Martinez Alonso $\mathrm{JC}^{1}$, Fernández Colino $\mathrm{T}^{1}$, Acevedo del Barrio $\mathrm{G}^{1}$, Gil Valiño $\mathrm{C}^{4}$, Eiris Aradas $\mathrm{MC}^{4}$

${ }^{I}$ Allergy Department, Hospital Virgen de la Concha Zamora, Spain ${ }^{2}$ Hematology Department, Hospital Virgen de la Concha Zamora, Spain ${ }^{3}$ Allergy Unit, University Hospital of Salamanca, Spain ${ }^{4}$ Pharmacy Unit, Hospital Virgen de la Concha Zamora, Spain

J Investig Allergol Clin Immunol 2019; Vol. 29(1): 68-69 doi: $10.18176 /$ jiaci.0335

Key words: Bendamustine. Desensitization. Non-Hodgkin lymphoma. Delayed hypersensitivity.

Palabras clave: Bendamustina. Desensibilización. Linfoma no Hodgkin. Hipersensibilidad tardía.

Bendamustine is an antineoplastic agent that was approved by the United States Food and Drug Administration in 2008 for use as monotherapy or in combination with other agents to treat chronic lymphocytic leukemia (CLL) and progressive indolent B-cell non-Hodgkin lymphoma (NHL) [1-3]

Although bendamustine is well tolerated, it can provoke allergic reactions and drug fever [4]. Symptoms are usually mild and include fever, chills, pruritus, and skin rash. However, in clinical trials, $3 \%$ of patients who were retreated with bendamustine experienced grade 3 or higher hypersensitivity reactions compared with those who were not retreated [5-7].

We describe a case of delayed-type hypersensitivity reaction to bendamustine with positive skin tests and design a new successful desensitization protocol with bendamustine.

In June 2017, 28-year-old man with NHL (T, NOS, stage II-A, IPI 0) received treatment with $\mathrm{CHOP}(\times 5)$, to which he did not respond. He started second-line therapy with ESHAP, and, again, there was no response after 2 cycles. Therefore, he received third-line therapy with GEMOX $(\times 3)$, which was followed by disease progression. On 26/02/2018 he started brentuximab vedotin (day 1) + bendamustine (days 1 and 2), without complications. A clinical response was recorded. On day 2 of the second cycle, 4 hours after administration, the patient experienced a sensation of poor temperature regulation, low-grade fever $\left(37.5^{\circ} \mathrm{C}\right)$, and pruritus and maculopapular eruptions on the trunk and extremities. The next day he presented facial and uvular angioedema and mild dyspnea. He was treated in the emergency department and referred to our outpatient allergic clinic.

After resolution of the clinical symptoms, prick tests with brentuximab $(5 \mathrm{mg} / \mathrm{mL})$ and bendamustine $(2.5 \mathrm{mg} / \mathrm{mL})$ and intradermal tests with brentuximab $(1 / 100,1 / 10)$ and bendamustine $(1 / 10,1 / 100)$ were performed. The immediate readings for the prick and intradermal tests were negative, although 6 hours later, the results of the intradermal test were positive with bendamustine (1/10 and $1 / 100)$. Intradermal tests with brentuximab were negative at both the immediate and the

Table. Bendamustine Desensitization Protocol

\begin{tabular}{|c|c|c|c|c|c|}
\hline $\begin{array}{l}\text { Bag } \\
\text { A } \\
\text { B }\end{array}$ & $\begin{array}{l}\mu g \\
1.5 \\
150\end{array}$ & $\begin{array}{l}\text { Saline, } \mathrm{mL} \\
250 \\
500\end{array}$ & $\begin{array}{c}\text { Concentration, } \mathrm{mg} / \mathrm{mL} \\
0.006 \\
0.3\end{array}$ & & \\
\hline \multicolumn{6}{|c|}{ (A: $5 \mathrm{ml}$ of "B" in $245 \mathrm{~mL}$ of saline) } \\
\hline Step & Solution & Rate, $\mathrm{mL} / \mathrm{h}$ & Time, $\min$ & Administered Dose, mg & Cumulative Dose, $\mathrm{mg}$ \\
\hline 1 & A & 2 & 15 & 0.003 & 0.003 \\
\hline 2 & A & 5 & 15 & 0.0075 & 0.0105 \\
\hline 3 & A & 10 & 15 & 0.015 & 0.0255 \\
\hline 4 & A & 20 & 15 & 0.03 & 0.0555 \\
\hline 5 & A & 50 & 15 & 0.075 & 0.1305 \\
\hline 6 & A & 100 & 15 & 0.15 & 0.2805 \\
\hline 7 & A & 200 & 15 & 0.3 & 0.5805 \\
\hline $8^{\mathrm{a}}$ & A & 400 & 15 & 0.6 & 1.1805 \\
\hline 9 & B & 20 & 15 & 1.5 & 2.6805 \\
\hline 10 & $\mathrm{~B}$ & 40 & 15 & 3 & 5.6805 \\
\hline 11 & B & 80 & 15 & 6 & 11.6805 \\
\hline 12 & $\mathrm{~B}$ & 160 & 15 & 12 & 23.6805 \\
\hline 13 & B & 200 & 15 & 15 & 38.6805 \\
\hline 14 & B & 250 & Rest & 111.3195 & 150 \\
\hline
\end{tabular}

aThe solution left over from the last step of bag A (step 8) is discarded. 
delayed readings. The results of laboratory tests including liver and kidney function and complete blood count were normal.

As bendamustine was considered to be essential for survival, a desensitization protocol was prepared, as follows: brentuximab on day 1 of the cycle and bendamustine on days 2 and 3 of the cycle. We designed a 14-step protocol in which the amount of bendamustine infused was $150 \mathrm{mg}$.

Two bags containing different concentrations of bendamustine were prepared. The patient was premedicated with antihistamines, corticosteroids, and an antileukotriene (montelukast). Given the possibility that the patient might present a late reaction, he was admitted to the hematology department.

On day 1 of the cycle, the patient tolerated $150 \mathrm{mg}$ of brentuximab. On the second day of the cycle, he received $150 \mathrm{mg}$ of bendamustine according to the protocol (Table). Four hours later, he presented a minimal nonpruriginous rash on the face and trunk. No fever was documented. On day 3 , the patient underwent another desensitization protocol with bendamustine. To prevent a delayed reaction, $60 \mathrm{mg}$ of methylprednisolone was administered intravenously 2 hours after the desensitization procedure. The patient tolerated this second dose of bendamustine without developing rash or other symptoms.

We report a case of delayed hypersensitivity reaction to bendamustine in which the skin tests confirmed the diagnosis. We also describe a new desensitization protocol to bendamustine. Both premedication and treatment with corticosteroids after desensitization were useful

To determine which drug caused the reaction, bendamustine and brentuximab were both evaluated using skin tests. As the alternatives are not sufficiently effective, a desensitization procedure with bendamustine was performed. The literature on desensitization is less extensive for delayed-type reactions than for immediate reactions; therefore, it is important to establish a protocol according to the drug and based on the patient's previous reaction [8].

Slower protocols tend to be more effective than rush protocols [9]; however, rush protocols have the advantage over slow protocols that full therapeutic doses of the drug can be reached within a few hours or 1 to 2 days. Nevertheless, the decision to choose a protocol must always be made on an individual basis after weighing up the risks and benefits.

Although several cases of hypersensitivity reaction to bendamustine have been described [5-7], there are only 3 reports of cases where an allergological workup was performed. Barbarroja-Escudero et al [4] reported the first 2 cases of delayed cutaneous hypersensitivity reactions with a positive allergological study.

Sangrador Pelluz et al [10] designed a protocol of desensitization of bendamustine. In this case, the patient experienced a delayed reaction with fever and cutaneous reaction. The intradermal test results were negative. The patient tolerated a 15 -step protocol with 3 bags at different concentrations.

To the best of our knowledge, we present the first case of successful desensitization to bendamustine in a delayed-type hypersensitivity reaction with positive skin test results.

Funding

The authors declare that no funding was received for the present study.

\section{Conflicts of Interest}

The authors declare that they have no conflicts of interest.

\section{References}

1. Leoni LM. Bendamustine: rescue of an effective antineoplastic agent from the mid-twentieth century. Semin Hematol. 2011;48(Suppl. 1):S4-S11.

2. O'Connor OA, Lue JK, Sawas A, Amengual JE, Deng , Kalac M, et al. Brentuximab vedotin plus bendamustine in relapsed or refractory Hodgkin's lymphoma: an international, multicentre, single-arm, phase 1-2 trial. Lancet Oncol. 2018 Feb; 19(2):25766.

3. Schöffski P, Hagedorn T, Grünwald V, Paul H, K. Merkle, R. Kowalski, et al. Repeated administration of short infusions of bendamustine: a phase I study in patients with advanced progressive solid tumours. J Cancer Res Clin Oncol. 2000;126:41-7.

4. Barbarroja-Escudero J, Sanchez-Gonzalez MJ, AntolinAmerigo D, Rodriguez-Rodriguez M, Alvarez-Mon M. Allergol Int. 2015 Jan;64(1):109-11.

5. Agencia Española del Medicamento y Productos Sanitarios: Levact 2,5mg/ml: Summary of Product Characteristics [Accessed 12 May 2013]. Available at: http://www.aemps. gob.es/cima/especialidad.do? metodo=verFichaWordPdf\&codi go $=72571 \&$ formato=pdf\&formulario=FICHAS\&file=ficha.pd http://www.aemps.gob.es/cima/especialidad.do?metodo=ver FichaWordPdf\&codigo $=72571 \&$ formato $=$ pdf\&formulario $=F \mid$ CHAS\&file=ficha.pd

6. Kusano $Y$, Terui Y, Yokoyama M, Hatake K. Lichenoid drug eruption associated with Bendamustine. Blood Cancer J. 2016;6(6):e438.

7. Fallon MJ, Heck JN. Fatal Stevens-Johnson sydrome/ toxic epidermal necrolysis induced allopurinol-rituximabbendamustine therapy. J Oncol Pharm Pract. 2015;21:388-92.

8. Scherer K, Brockow K, Aberer W, Gooi JH, Demoly P, Romano $A$, et al. Desensitization in delayed drug hypersensitivity reactions - an EAACI position paper of the Drug Allergy Interest Group. Allergy. 2013;68(7):844-52.

9. Demir S, Olgac M, Saglam S, Gelincik A, Colakoglu $B_{1}$ Buyukozturk S. Sucessful Capecitabine Desensitization for a Delayed-Type Hipersensitivity reaction. J Investig Allergol Clin Immunol. 2016; Vol. 26(1):66-7.

10. Sangrador Pelluz C, Luis Hidalgo MM, Martinez Garcia M, Pérez Serrano Lainosa MD, Soler Company E. Toxicodermia by bendamustine: development of a desensization protocol. Farm Hosp. 2013;37(5):421-3.

- Manuscript received July 24, 2018; accepted for publication, October 8, 2018.

Cristina Martin Garcia Allergy Department Hospital Virgen de la Concha 49022 Zamora, Spain

E-mail: crismartines@yahoo.es 